\title{
Analysis of potential liquefaction of sandy soils using effective confining pressure
}

\author{
Siti Nur Indah Sari ${ }^{1 *}$ \\ ${ }^{1}$ Magister Program, Civil Engineering Dept., Faculty of Engineering, Andalas University, Padang
}

\begin{abstract}
Earthquake disasters are some of the most frequent disasters in the world. One of the impacts of earthquakes is liquefaction. Indonesia is earthquake-prone and has been negatively impacted by liquefaction. Recently liquefaction resulting from an earthquake in Palu, Central Sulawesi caused losses in terms of material and lives motivating a more detailed study of this risk to reduce it in the future. In this study, an analysis of the liquefaction potential of sandy soil was carried out by varying the effective confining pressure to produce a graph relating fine contents (FC) to cyclic resistance ratio (CRR). The value of the cyclic resistance ratio is needed to determine the safety factor for potential liquefaction.
\end{abstract}

\section{Introduction}

Indonesia is located on the 'Pacific Ring of Fire' [1] so often experiences earthquakes of varying magnitudes. Some of these trigger liquefaction. Liquefaction of the soil is a phenomenon where the soil becomes saturated so that it loses rigidity due to stress, such as from earthquakes, which suddenly causes the soil to turn into a liquid like material. As illustrated in Fig. 1:

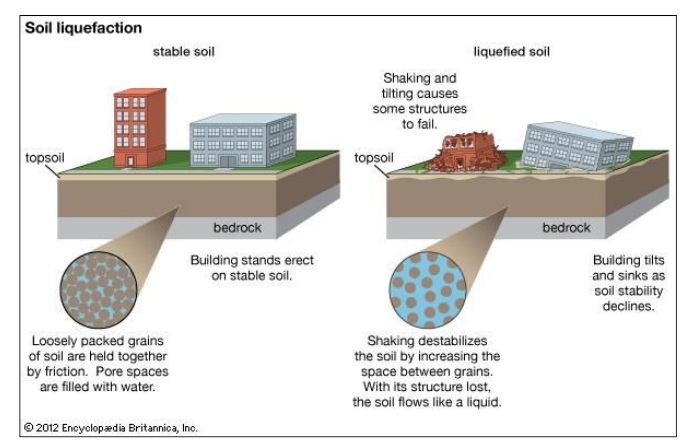

Fig 1. Process of liquefaction.

Liquefaction can result in the movement of soil burying victims, damaging buildings and infrastructure and causing collapse of buildings as the strength of the land supporting them is lost.One liquefaction disaster that claimed many lives occurred in Palu on 28 September 2018, especially in Petobo and Balaroa Subdistricts in conjunction with an earthquake of magnitude 7,4 SR.

In Balaroa 82 people died and 1,405 houses were destroyed, while in Petobo 104 people were killed and 2,050 houses damaged .Fig. 2 shows, a comparison of satellite images in Petobo, after and before the liquefaction. Fig.s 3 and 4 show damage caused by liquefaction disasters.

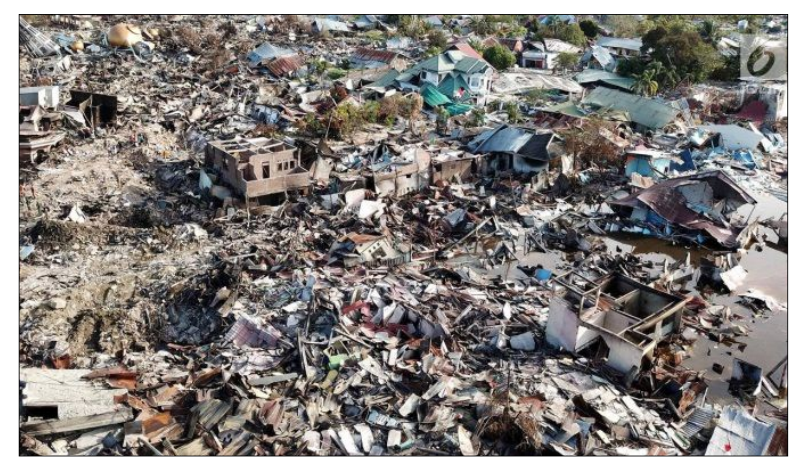

Fig 2. Satellite Imagery of Petobo

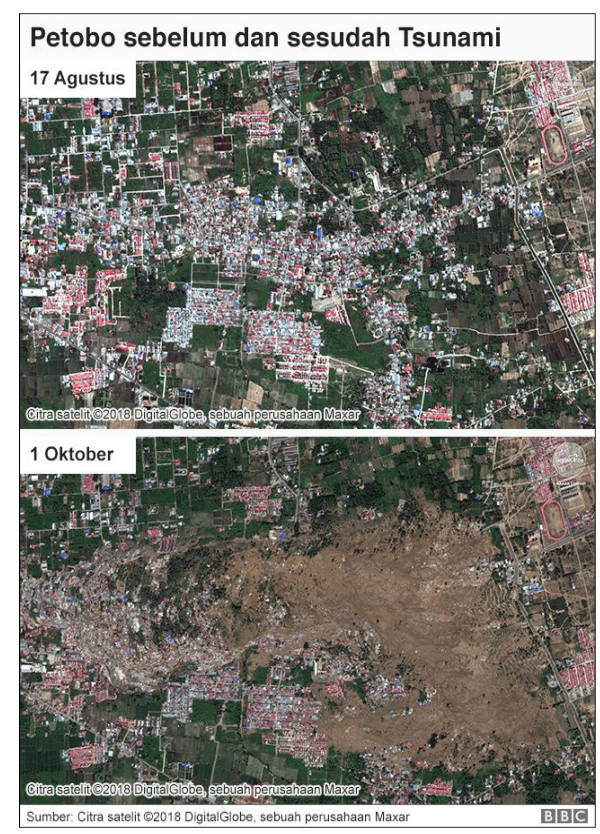

Fig 3. Conditions after liquefaction in Balaroa

\footnotetext{
* Corresponding author: sariindah589@gmail.com
} 


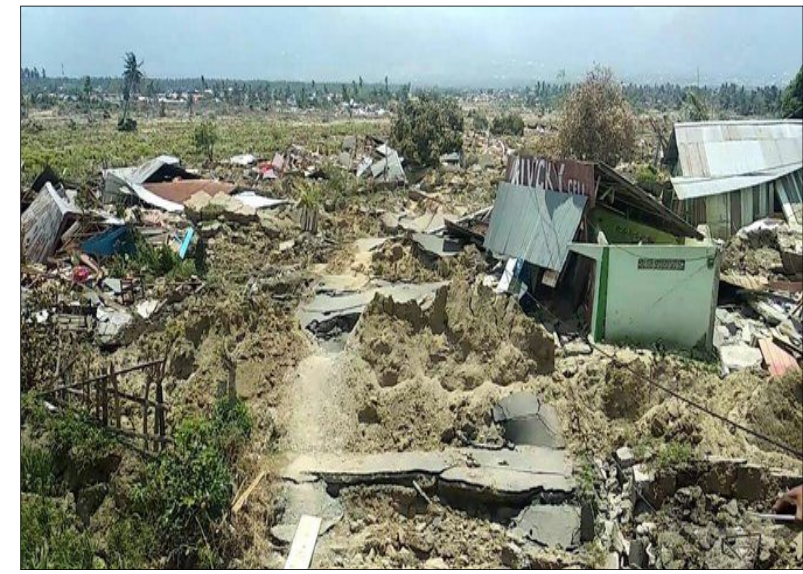

Fig 4. Conditions after liquefaction in Petobo

To mitigate such disasters, analysis of the potential of liquefaction in areas that may be vulnerable is necessary. There are various methods to analyze the potential for liquefaction in the field and in the laboratory including Cone Penetration Test data,and the Seed and Idriss calculation method [2],[3], [4], determined liquefaction potential using N-SPT data (Standard Penetration Test), and the Idriss and Boulanger method predicted the liquefaction that occurred in the Bengkulu city area from the September 12, 2007, magnitude 8.6 earthquake well [5], also found that N-SPT rather than Seed and Idriss predicted the liquefaction that occurred at Bitung pier in North Sulawesi [6], determined liquefaction risk in the laboratory- based on a grain size analysis using a sieve test from which gradient curves were constructed.

Liquefaction testing in the laboratory has also been conducted using a triaxial test, which can determine the potential for liquefaction from cyclic loads [7]. The potential of liquefaction can also be predicted by measuring the effective confining pressure for various CRR value and construction a graph of cyclic resistance ratio (CRR) against Fine Contents (FC) from which the safety factor for liquefaction can be calculated. The safety factor value is an important predictor of potential liquefaction in sandy soil. This method because it only requires shallow samples of soil. Hence, this is the method chosen for the present study.

\section{METHODOLOGY}

\subsection{Preliminary Investigation}

Samples were taken from 6 different locations where there are important structures such as school, mosque, or state-owned companies, where analysis of potential liquefaction could gauge the risk of damage to these buildings. The six sites were : 1) Pariaman Beach (Floating Mosque of Kota Pariaman), 2) Poltekpel School (Ketaping), 3) Rusunawa (Tabing), 4) Padang Beach (Behind UNP Campus), 5) Teluk Bayur Port, 6) Pertamina, Bungus. Samples were taken to a depth of 30 $\mathrm{cm}$.

\subsection{Index Properties of Soil}

Relative density (Dr) can also be expressed in terms of maximum and minimum dry unit weight, which can be calculated by the formula:

$$
\begin{aligned}
D_{r} & =\frac{\left[\frac{1}{\gamma_{d(\min )}}\right]-\left[\frac{1}{\gamma_{d}}\right]}{\left[\frac{1}{\gamma_{d(\min )}}\right]-\left[\frac{1}{\gamma_{d(\text { maks })}}\right]} \\
& =\left[\frac{\gamma_{d}-\gamma_{d(\text { min })}}{\gamma_{d(\text { maks })}-\gamma_{d(\text { min })}}\right]\left[\frac{\gamma_{d(\text { maks })}}{\gamma_{d}}\right]
\end{aligned}
$$

Where :

$\gamma_{d(\min )}$ is Dry unit weight in the loosest state; (that is, when the void ratio is, e maks)

$\gamma_{d} \quad$ is in situ dry unit weight (in situ void ratio, e)

$\gamma_{d \text { (maks) }}$ is Dry unit weight in the densest state; (that is, when the void ratio is, $\mathrm{e}_{\min }$ )

The weight relationships are moisture content, moist unit weight, dry unit weight, often defined as follows:

$$
\text { Moisture content }=w \%=\left(\frac{W_{w}}{W_{S}}\right) \times 100 \%
$$

Where:

$W_{\mathrm{s}}$ is Weight of the soil solids

$W \mathrm{~W}$ is Weight of water

$$
\text { Moist unit weight }=\gamma=\frac{W}{V}
$$

Where:

$\mathrm{W}$ is Total weight of the soil specimen $=W \mathrm{~s}+W_{\mathrm{W}}$

$\mathrm{V}$ is Total volume of soil

$$
\text { Dry unit weight }=\gamma d=\frac{\gamma}{1+w}
$$

Where:

$\gamma$ is Moist unit weight

$\mathrm{W}$ is Moisture content

\subsection{Sieve Analysis Test}

The sieve analysis test determined the value of FC (Fine Contents) from sand soil samples by determining the percent of the sample which passed throught a filter no. 200 .

\subsection{Eartquake Acceleration (a max)}

Earthquake acceleration of the bedrock can be calculated using the atenuase function which describes the correlation between the eartquake acceleration (a max), Earthquake Magnitude (Mw) and the distance (r) from the earthquake epicenter.

Atenuase function formula calculated by Joyner \& Boore:

$$
a=10^{\left[0.71+0.23\left(M_{w}-6\right)-\log (r)-0.0027 r\right]}
$$




\subsection{Reduction Factor $(\mathrm{rd})$}

The reduction factor is a value that can affect stresses in the soil.The deeper the soil, the smaller the reduction factor [8]. Following is the formula (rd) proposed by $\mathrm{T}$. F. Blake.

The formulae is:

$$
\mathrm{rd}=\frac{1.0-0.4113 \mathrm{z}^{1.5}+0.04052 \mathrm{z}+0.001753 \mathrm{z}^{1.5}}{1.0-0.4117 \mathrm{z}^{0.5}+0.05729-0.006205 \mathrm{z}^{1.5}+0.00121 \mathrm{z}^{2}}
$$

where $\mathrm{z}$ is the depth of the soil layer

\subsection{Cyclic Stress Ratio (CSR)}

Cyclic Stress Ratio is a cyclic stress due to an earthquake divided by effective stress. Seed and Idriss (1971) calculated the equation for the ratio cyclic stress (CSR), the formulae is:

$$
\operatorname{CSR}=\frac{\tau c}{\sigma^{\prime}}=\frac{0,65 \cdot \gamma \cdot z \cdot \frac{a \max }{g} \cdot r d}{\sigma^{\prime}}
$$

Where :

$\begin{array}{lll}\tau c & \text { is Cyclic Shear Stress }(\mathrm{kPa}) \\ \sigma & \text { is Confining pressure }(\mathrm{kPa}) \\ \mathrm{z} & \text { is Dept } & (\mathrm{m}) \\ \gamma & \text { is Unit Weight } & \left(\mathrm{g} / \mathrm{cm}^{3}\right) \\ \mathrm{g} & \text { is Gravitation } & \left(\mathrm{m} / \mathrm{s}^{2}\right) \\ \mathrm{a} \mathrm{max}_{\max } & \text { is Earthquake acceleration }\end{array}$

The effective confining pressure that were used were between $60 \mathrm{kPa}, 120 \mathrm{kPa}$, and $240 \mathrm{kPa}$ [9].

\subsection{CRR (Cyclic Resistance Ratio)}

Several formulae can be used to determine CRR value, including N-SPT data, Artificial Neural Networks [10], but for this research, CRR was obtained from the CRR vs FC graphs, according to Baziar and Sharafi (2011) who obtained CRR values from these graphs as below.

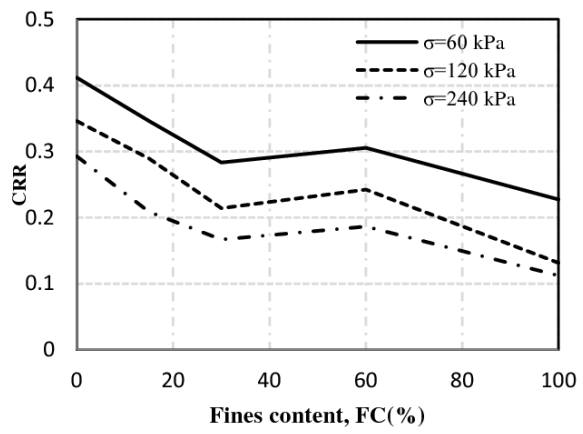

Fig 5: FC (Fine Contents) vs CRR ( Cyclic Resistence Ratio ) Baziar and Sharafi (2011).

\subsection{FS (Safety Factor)}

To determine the liquefaction potential, you can use the following formula:
$\mathrm{FS}=\mathrm{CRR} / \mathrm{CSR}$

When:

If $\mathrm{FS}$ value is $<1=$ liquefaction

If $\mathrm{FS}$ value is $>1=$ no liquefaction

\section{Result and Discussion}

Data of the sand based on index properties as follows:

Table 1: Index properties of soil

\begin{tabular}{|c|c|c|c|c|}
\hline Sampel & $\gamma(\mathbf{g r} / \mathbf{c m} 3)$ & W (\%) & Dr & GS \\
\hline 1 & 1.778 & 8.820 & 3.712 & 2.658 \\
\hline 2 & 1.611 & 5.450 & 2.196 & 2.660 \\
\hline 3 & 1.473 & 8.870 & 1.819 & 2.659 \\
\hline 4 & 1.644 & 9.410 & 1.668 & 2.655 \\
\hline 5 & 1.490 & 7.870 & 1.697 & 2.654 \\
\hline 6 & 1.622 & 5.480 & 1.303 & 2.664 \\
\hline
\end{tabular}

CRR value was obtained of the graph Fig. 5, by Baziar and Sharafi (2011):

Table 2: CRR value from confining pressure

\begin{tabular}{|c|c|c|c|c|}
\hline Sampel & FC\% & $\begin{array}{c}\text { CRR } \boldsymbol{\sigma}^{\prime}= \\
\mathbf{6 0} \mathbf{~ k P a}\end{array}$ & $\begin{array}{c}\text { CRR } \boldsymbol{\sigma}^{\prime}= \\
\mathbf{1 2 0} \mathbf{~ k P a}\end{array}$ & $\begin{array}{c}\text { CRR } \boldsymbol{\sigma}^{\prime}= \\
\mathbf{2 4 0} \mathbf{~ k P a}\end{array}$ \\
\hline 1 & 3 & 0.382 & 0.305 & 0.263 \\
\hline 2 & 2.47 & 0.390 & 0.320 & 0.270 \\
\hline 3 & 3.03 & 0.380 & 0.303 & 0.261 \\
\hline 4 & 1.17 & 0.405 & 0.338 & 0.279 \\
\hline 5 & 0 & 0.415 & 0.345 & 0.290 \\
\hline 6 & 0.07 & 0.412 & 0.343 & 0.286 \\
\hline
\end{tabular}

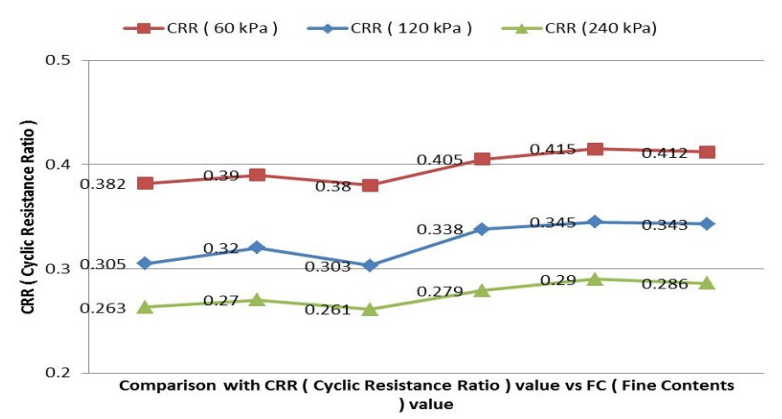

Fig 6: CRR value for containing pressure

The higher the value of the pressure produced, the smaller the potential for liquefaction because with high pressure, the soil becomes dense and the bond between the granules gets stronger which results in smaller soil pores, so liquefaction is less likely to occur.

The value of earthquake acceleration (a max), reduction factors ( $\mathbf{r d})$ and cyclic stresses $(\boldsymbol{\tau} \mathbf{c})$ obtained as follows: 
Table 3: Reduction factor, earthquake acceleration, and cyclic stress

\begin{tabular}{|c|c|c|c|}
\hline Sampel & rd & a max & $\boldsymbol{\tau}$ \\
\hline 1 & 0.994 & 0.249 & 29.164 \\
\hline 2 & 0.994 & 0.174 & 18.470 \\
\hline 3 & 1.200 & 0.130 & 4.566 \\
\hline 4 & 1.200 & 0.106 & 4.157 \\
\hline 5 & 1.200 & 0.087 & 3.091 \\
\hline 6 & 1.200 & 0.092 & 3.559 \\
\hline
\end{tabular}

The farther the distance of the epicenter, the smaller the earthquake acceleration. Facilities / infrastructure such as schools, hospitals, government offices, close to potential earthquake epicenters needs to be designed with consideration of the possibility of liquefaction.

To determine liquefaction potential in soil samples, the value of safety factor (FS) at each pressure is calculated, if the value of FS $>1$, then liquefaction will not occur, and the if FS $<1$, then the potential for liquefaction is very high.

Table 4: Confining pressure $\sigma^{\prime}=60 \mathrm{kPa}$

\begin{tabular}{|c|c|c|c|c|c|}
\hline Sampel & $\begin{array}{c}\boldsymbol{\sigma}^{\prime} \\
(\mathbf{k P a})\end{array}$ & $\mathbf{C S R}$ & $\mathbf{C R R}$ & $\mathbf{F S}$ & Ket \\
\hline 1 & 60 & 0.486 & 0.382 & 0.786 & yes \\
\hline 2 & 60 & 0.308 & 0.390 & 1.267 & no \\
\hline 3 & 60 & 0.076 & 0.380 & 4.994 & no \\
\hline 4 & 60 & 0.069 & 0.405 & 5.846 & no \\
\hline 5 & 60 & 0.052 & 0.415 & 8.055 & no \\
\hline 6 & 60 & 0.059 & 0.412 & 6.946 & no \\
\hline
\end{tabular}

Table 5: Confining pressure $\sigma^{\prime}=120 \mathrm{kPa}$

\begin{tabular}{|c|c|c|c|c|c|}
\hline Sampel & $\begin{array}{c}\boldsymbol{\sigma}^{\prime} \\
(\mathbf{k P a})\end{array}$ & \multicolumn{1}{c|}{ CSR } & CRR & FS & Ket \\
\hline 1 & 120 & 0.243 & 0.305 & 1.255 & no \\
\hline 2 & 120 & 0.154 & 0.320 & 2.079 & no \\
\hline 3 & 120 & 0.038 & 0.303 & 7.964 & no \\
\hline 4 & 120 & 0.035 & 0.338 & 9.758 & no \\
\hline 5 & 120 & 0.026 & 0.345 & 13.393 & no \\
\hline 6 & 120 & 0.030 & 0.343 & 11.565 & no \\
\hline
\end{tabular}

Table 6: Confining pressure $\sigma^{\prime}=240 \mathrm{kPa}$

\begin{tabular}{|c|r|r|c|c|c|}
\hline Sampel & $\begin{array}{c}\boldsymbol{\sigma}^{\prime} \\
(\mathbf{k P a})\end{array}$ & \multicolumn{1}{c|}{ CSR } & \multicolumn{1}{c|}{ CRR } & FS & Ket \\
\hline 1 & 240 & 0.122 & 0.263 & 2.164 & no \\
\hline 2 & 240 & 0.077 & 0.270 & 3.508 & no \\
\hline 3 & 240 & 0.019 & 0.261 & 13.720 & no \\
\hline 4 & 240 & 0.017 & 0.279 & 16.109 & no \\
\hline 5 & 240 & 0.013 & 0.290 & 22.516 & no \\
\hline 6 & 240 & 0.015 & 0.286 & 19.287 & no \\
\hline
\end{tabular}

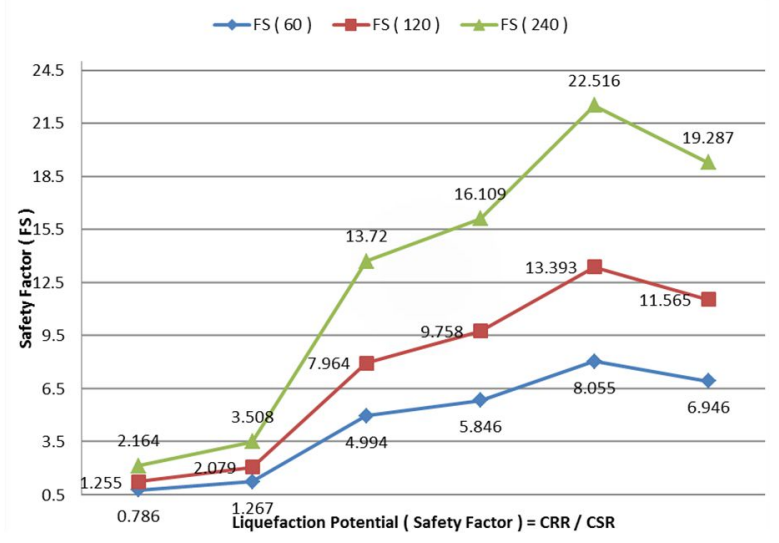

Fig 7: Safety Factor for containing pressure

From the FC vs CRR graph with confining pressure $60 \mathrm{kPa}$, (Baziar and Sharafi: 2011) the highest CRR value was for Fine Contents $0 \%,(0,415 \mathrm{kPa})$. As the confining pressure increase to $120 \mathrm{kPa}$ and then to 240 $\mathrm{kPa}$, the CRR values dropped to 0,345 and $0,290 \mathrm{kPa}$ respectively.

The highest CSR value was $0,486 \mathrm{kPa}$ for confining pressure $60 \mathrm{kPa}$ which dropped to $0,243 \mathrm{kPa}$ for $120 \mathrm{kPa}$ and $0,122 \mathrm{kPa}$ for $240 \mathrm{kPa}$.

CSR is inversely proportional to CRR and it was found that if the CRR value is higher than the CSR value the potential for liquefaction is low.

The safety factor value for liquefaction at $60 \mathrm{kPa}$ pressure was 0,786 for soil from one location (Floating Mosque of Kota Pariaman) tested indicating that site could be at risk of liquefaction in case of an earthquake.

\section{Conclusion}

The results of this study indicate that several of the large public buildings in the coastal area around Padang and Pariaman city are build on soil that could experience liquefaction in case of an earthquake. As this area is also earthquake-prone it could be suggested that future construction of such public structures be conducted further inland in areas with soils that are less likely to suffer from liquefaction under pressure. Failing that construction methods that are less vulnerable to liquefaction need to be investigated for buildings in these areas.

\section{References}

1. F. Pratama, A. S. Budi, Wibowo, Jnl Oln Mtrk Tnk, 2 (2014)

2. A. Hakam, H. G. Putra, D. Lastaruna, Jnl Rkys Spl 5 (2009)

3. H. Warman, D. Y. Jumas, Jnl Rkya Spl 9 (2013)

4. L. Z. Mase, Jnl Trts Trpn Bdg Rkya Spl 24, 11-16 (2017)

5. K. C. Tijow, O. B. A. Sompie, J. H. Ticoh, Jnl Spl Sik 6, 491-500 (2018)

6. S. P. O. Siahaan, Tugas Akhir S1, 60-61 (Padang, 2015) 
7. L. Bjerrum, S. Kringstad, O. Kummeneje, The Shear Strength of a Fine Sand (NGI, 1961)

8. T. L. Youd, Jnl Gtchncl Gevrmntl Engg 127, 817833 (2001)
9. M. Baziar, H. Sharafi, S Dnmc Ertqke Engg 31, 857-865 (2011)

10. H. Sharafi, S. Jalili, Opn Jnl Cvl Engg 4, 217-228 (2014) 